\title{
ROLE OF PROPHYLACTIC TRANEXAMIC ACID IN REDUCING BLOOD LOSS DURING ELECTIVE CESAREAN SECTION
}

\author{
By
Ahmed Mohamed El-Seadawy Ghanem, Mofeed Fawzy Mohamed and Samir Khamis Galal

Obstetrics and Gynecology Department, Faculty of Medicine, Al-Azhar University

E-mail: elseadawy855@gmail.com.

\begin{abstract}
Background: Post-partum hemorrhage (PPH) is a major cause of maternal mortality globally. Tranexamic acid, an anti-fibrinolytic agent is an attempt to prevent this complication.

Objective: To identify the efficacy of intravenous (IV) tranexamic acid in reducing blood loss during elective cesarean section (CS).

Patients and Methods: A Randomized Controlled Study was conducted on 200 women undergoing cesarean section. They were allocated to either Study or Control group by computer generated random number tables. Tranexamic acid (TXA) was given prior to surgery in study group in addition to the routine care (10 units of oxytocin added to the intravenous drip soon after baby delivery), whereas the control group had routine care alone. Blood loss was measured in both groups. Hemoglobin before and after surgery was estimated, and the percentage of difference was compared.

Results: There was a significant reduction in blood loss calculated from placental delivery till end of surgery: $391.95 \mathrm{ml}$ in study group versus $633 \mathrm{ml}$ in control group $(\mathrm{p}<0.000)$. Another parameter studied was the percentage of fall in hemoglobin before and after surgery. Postoperative hemoglobin was significantly higher in study group than control group $(\mathrm{p}<0.000)$; Reduction in hemoglobin was significantly less in study group than control group by $(0.76 \pm 0.29 \mathrm{gm} / \mathrm{dl})(\mathrm{p}<0.000)$. There were no immediate post-operative complications to the mother and neonate.
\end{abstract}

Conclusion: Tranexamic acid (TXA) significantly reduced the amount of blood loss during Elective Cesarean Section (CS). Use of TXA was not associated with adverse effects. Thus, TXA can be used safely and effectively in subjects undergoing CS.

Keywords: Fibrinolysis, Hemoglobin, Hemorrhage, Morbidity, Prevention, TXA.

\section{INTRODUCTION}

Cesarean section (CS) rate has increased in both developed and developing countries, which would result in an increased risk of PPH. Deaths due to $\mathrm{PPH}$ remain relatively common in some parts of the world. To lower this occurrence, it is very vital to reduce blood loss in CS (IKarnbo et al., 2012).
Management of hemorrhage after CS may range from administration of oxytocic and blood transfusion to more radical measures such as hysterectomy and use of anti-fibrinolytic agent such as tranexamic acid (TXA) (Ray et al., 2017).

A systematic review of randomized controlled trials of anti-fibrinolytic agents in elective surgical patients identified 211 
randomized controlled trials. Prohaemostatic drugs such as Tranexamic acid provide a complementary biochemical haemostatic effect to the well proven uterotonics, especially oxytocin. Systemic anti-fibrinolytic agents are widely used in surgery (Henry et al., 2015).

Tranexamic acid has been shown to reduce uterine blood loss in non-surgical aspect. A study done on women with menorrhagia has showed significant reduction in mean menstrual blood loss in those treated with Tranexamic acid (Matteson et al., 2013).

The results showed that Tranexamic acid reduced the risk of blood transfusion by $39 \%$. Tranexamic acid is an analogue of lysine that inhibits fibrinolysis by competitively binding to plasminogen. It prevents the lysis of formed clot by inhibiting activation of plasminogen and plasmin. It is ten times more potent than Amino- caproic acid (Viswanath et al., 2015).

Several Randomised controlled trials have analysed the prophylactic role of Tranexamic acid and have shown significant results in reducing blood loss, Tranexamic acid might reduce the need for hysterectomy, reduce the risk of severe anaemia and avoid the need for blood transfusion; hence, this could contribute significantly to the goal of reducing maternal mortality (Movafegh et al., 2011).

This work aimed to identify the efficacy of intravenous (IV) tranexamic acid in reducing blood loss during elective cesarean section (CS).

\section{PATIENTS AND METHODS}

A Randomized Controlled Study established in the branch of Obstetrics and Gynecology at Al-Hussein University Hospital and Mabrra Elmahalla Health Insurance from the first of May 2020 to the first of December 2020.

\section{Inclusion Criteria:}

- Parity not more than two.

- Singleton pregnancy.

- Delivery by elective LSCS.

- Subjects of age between 18 and 37 years.

- Gestational age of 37 to 42 weeks of pregnancy.

\section{Exclusion Criteria:}

- Parity more than two.

- Twin pregnancy.

- Vaginal delivery or urgent C.S.

- Subjects of age less than 18 or more than 37.

- Subjects having medical problems like gestational hypertension, chronic hypertension and severe pre-eclampsia, renal disease, heart disease complicating pregnancy and having coagulation disorders.

- Subjects allergic to Tranexamic acid by previous history of allergy to it.

- Subjects with history of thromboembolic disorders.

- Subjects having tendency for increased bleeding like abnormal placentation, multiple pregnancy, polyhydramnios, previous two or more cesarean sections, and those who had blood transfusion due to anemia. 
Blood loss was measured in both groups following placental delivery till the end of surgery. Blood collected in the suction container was noted, Soaked mops and operation table perineal sheet were weighed by electronic scale before and after the surgery. Blood collected in suction container, Amniotic fluid and the volume of blood lost before placental delivery were not included in the study. Hemoglobin and hematocrite value before and after surgery were estimated, and the percentage of difference was compared.

\section{Participant:}

The study was conducted among subjects at the Department of Obstetrics and Gynecology of Al-Hussein University Hospital and Mabrra Elmahalla Health Insurance who were to undergo elective cesarean section, after confirming the eligibility criteria for inclusion. All women had given a written consent after they were informed about the study aims and benefits. This research included 200 pregnant women who were divided into 2 equal groups:
Group I: Tranexamic acid was given prior to surgery in study group in addition to the routine care (10 units of oxytocin added to the intravenous drip soon after baby delivery).Tranexamic acid injection was prepared by diluting $1 \mathrm{~g}(10 \mathrm{ml})$ TXA in $100 \mathrm{ml}$ of normal saline. TXA was administrated as intravenous infusion (over 15minutes) at least 20 minutes prior to skin incision.

Group II: Control group who had routine care alone.

\section{Statistical analysis:}

Information were gathered, amended, implicit and entered to the Factual Bundle for Sociology (IBM SPSS) variant 20 (statistical package for the social sciences) data were summarized as mean \pm Standed deviation, range and percentage. Both independent and paired t-test or MannWhitney U test were used for comparison of means. Chi square for comparison of qualitative data the P-value was considered significant when $\mathrm{p} \leq 0.05$.

\section{RESULTS}

This work included 200 pregnant women, divided into study (tranexamic) and control groups. No Significant difference between tranexamic and control groups regarding maternal age and gestational age, medical history, drug allergy, parity and gravidity (Table 1). 
Table (1): Comparison between tranexamic and control groups regarding to maternal age, gestational age (GA), medical history, drug allergy, parity and gravidity

\begin{tabular}{|c|c|c|c|c|}
\hline \multirow{2}{*}{\multicolumn{2}{|c|}{$\begin{array}{ll}\text { Parameters } & \text { Groups } \\
\end{array}$}} & Group 1 & Group 2 & \multirow{2}{*}{ P-value } \\
\hline & & No. $=100$ & No. $=100$ & \\
\hline \multirow{2}{*}{ Maternal age } & Mean \pm SD & $28.51 \pm 3.42$ & $29.15 \pm 3.64$ & \multirow{2}{*}{0.202} \\
\hline & Range & $23-37$ & $23-37$ & \\
\hline \multirow{3}{*}{ Gravidity } & PG & $39(39.0 \%)$ & $35(35.0 \%)$ & \multirow{3}{*}{0.838} \\
\hline & 2 & $52(52.0 \%)$ & $55(55.0 \%)$ & \\
\hline & 3 & $9(9.0 \%)$ & $10(10.0 \%)$ & \\
\hline \multirow{3}{*}{ Parity } & $\mathbf{0}$ & $39(39.0 \%)$ & $35(35.0 \%)$ & \multirow{3}{*}{0.769} \\
\hline & 1 & $55(55.0 \%)$ & $60(60.0 \%)$ & \\
\hline & 2 & $6(6.0 \%)$ & $5(5.0 \%)$ & \\
\hline \multirow{2}{*}{$\begin{array}{l}\text { Gestational age } \\
\text { (weeks) }\end{array}$} & Mean \pm SD & $38.34 \pm 0.68$ & $38.25 \pm 0.54$ & \multirow{2}{*}{0.301} \\
\hline & Range & $37-40$ & $37-39$ & \\
\hline Medical history & Negative & $100(100.0 \%)$ & $100(100.0 \%)$ & - \\
\hline Drug allergy & Negative & $100(100.0 \%)$ & $100(100.0 \%)$ & - \\
\hline
\end{tabular}

There was a significant difference placental delivery to the end of the between tranexamic acid group and surgery (Table 2).

control group regarding blood loss from

Table (2): Comparison between tranexamic and control groups regarding blood loss from placental delivery to the end of the surgery $(\mathrm{mL})$

\begin{tabular}{|c|c|c|c|}
\hline Groups & Group 1 & Group 2 & \multirow{2}{*}{ P-value } \\
\hline Blood loss & No. $=100$ & No. $=100$ & \\
\hline Mean \pm SD & $391.95 \pm 33.54$ & $633 \pm 16.55$ & \multirow{2}{*}{$<0.001$} \\
\hline Range & $340-460$ & $600-660$ & \\
\hline
\end{tabular}

There was no significantly difference between two groups regarding preoperative hemoglobin, while there was a significant difference between tarnexamic group and control group regarding postoperative hemoglobin (Table 3).

Table (3): Comparison between tranexamic and control groups regarding hemoglobin $(\mathrm{g} / \mathrm{dL})$

\begin{tabular}{|c|c|c|c|c|}
\hline \multirow{2}{*}{\multicolumn{2}{|c|}{$\begin{array}{ll}\text { Parameters } & \text { Groups } \\
\end{array}$}} & Group 1 & Group 2 & \multirow{2}{*}{ P-value } \\
\hline & & No. $=100$ & No. $=100$ & \\
\hline \multirow{2}{*}{ Hb before } & Mean \pm SD & $10.91 \pm 1$ & $11.14 \pm 0.96$ & \multirow{2}{*}{0.099} \\
\hline & Range & $8.5-12.9$ & $8.8-13$ & \\
\hline \multirow{2}{*}{ Hb after } & Mean \pm SD & $10 \pm 1.05$ & $9.48 \pm 0.91$ & \multirow{2}{*}{$<0.001$} \\
\hline & Range & $7.9-12.3$ & $7.3-11.5$ & \\
\hline \multirow{2}{*}{ Paired t-test } & $\mathbf{T}$ & 14.890 & 52.579 & \\
\hline & P-value & $<0.001$ & $<0.001$ & \\
\hline
\end{tabular}


There was a significant difference between tranexamic group and control group regarding hemoglobin reduction (Table 4).

Table(4): Comparison between tranexamic and control groups regarding hemoglobin reduction $\mathrm{g} / \mathrm{dl}$

\begin{tabular}{|c|c|c|c|}
\hline Groups & Group 1 & Group 2 & \multirow{2}{*}{ P-value } \\
\hline HB difference & No. $=100$ & No. $=100$ & \\
\hline Mean \pm SD & $-0.91 \pm 0.61$ & $-1.67 \pm 0.32$ & \multirow{2}{*}{0.001} \\
\hline Range & $-2.2-0.4$ & $-2.7--1.3$ & \\
\hline
\end{tabular}

There was no significantly difference between two groups regarding preoperative hematocrit value, while there was a significant difference between tranexamic group and control group regarding postoperative hematocrit value (Table 5).

Table (5): Comparison between tranexamic and control groups regarding hematocrit percent

\begin{tabular}{|c|c|c|c|c|}
\hline \multirow{2}{*}{ Parameters } & Groups & Group 1 & Group 2 & \multirow{2}{*}{ P-value } \\
\cline { 3 - 5 } Haemtocrite before & Mean \pm SD & $\mathbf{3 4 . 6 8} \pm \mathbf{3 . 3 2}$ & $\mathbf{3 4 . 1 5} \pm \mathbf{2 . 8}$ & \multirow{2}{*}{0.220} \\
\cline { 3 - 5 } & Range & $\mathbf{2 6 . 5}-\mathbf{4 2 . 1}$ & $\mathbf{2 6 . 1}-\mathbf{4 2 . 1}$ & \\
\hline \multirow{2}{*}{ Haemtocrite after } & Mean \pm SD & $\mathbf{2 9 . 8 6} \pm \mathbf{3 . 0 9}$ & $\mathbf{2 8 . 6 2} \pm \mathbf{2 . 7 6}$ & \multirow{2}{*}{0.003} \\
\cline { 2 - 4 } & Range & $\mathbf{2 1 . 7 - 3 5}$ & $\mathbf{2 4 - 3 7}$ & \\
\hline \multirow{2}{*}{ Paired t-test } & T & $\mathbf{5 2 . 4 0 2}$ & $\mathbf{2 5 . 8 0 4}$ & \\
\cline { 2 - 4 } & P-value & $<\mathbf{0 . 0 0 1}$ & $<\mathbf{0 . 0 0 1}$ & \\
\hline
\end{tabular}

There was a significant difference between tranexamic group and control group regarding hematocrit reduction (Table 6).

Table (6): Comparison between tranexamic and control groups regarding hematocrit reduction $(\%)$

\begin{tabular}{|c|c|c|c|}
\hline Groups & Group 1 & Group 2 & \multirow{2}{*}{ P-value } \\
\hline Haemtocrite difference & No. $=100$ & No. $=100$ & \\
\hline Mean \pm SD & $-4.82 \pm 0.92$ & $-5.52 \pm 2.14$ & \multirow{2}{*}{0.003} \\
\hline Range & $-7.1--3$ & $-12.2-2.4$ & \\
\hline
\end{tabular}

\section{DISCUSSION}

Obstetric hemorrhage remains one of the major causes of maternal death in both developed and developing countries. Because of its importance as a leading cause of maternal mortality and morbidity, and because of evidence of substandard care in the majority of fatal cases, obstetric hemorrhage must be considered as a priority topic for national research development (Ducloy-Bouthors et al., 2016).

During placental delivery, fibrinogen and fibrin are rapidly degraded, whereas plasminogen activators and fibrin degradation products increase due to activation of the fibrinolytic system. This activation can last up to 6-10 h 
postpartum; causing more bleeding. Tranexamic acid competitively inhibits activation of plasminogen; thereby reducing conversion of plasminogen to plasmin (fibrinolysin).The antifibrinolytic potency of tranexamic acid was approximately 5 to 10 times that of aminocaproic acid. It was used in gynecological bleeding and major trauma (Viswanath et al., 2015).

Our study showed significant difference between tranexamic and controls as regards to blood loss and hemoglobin difference.

In our study, there was no significant difference as regard patient characteristics age, weight, parity and gestational age between study and control groups. This went with Movafegh et al. (2011), Goswami et al. (2013), Wang et al. (2015) and Lakshmi et al. (2016) who founded that patients' characteristics in the study and control groups were similar, with no statistical difference between the two groups.

In our study, tranexamic acid significantly reduced bleeding during and after cesarean section. The study total blood loss was significantly less than control group these results agreed with the results of the three mentioned studies.

Goswami et al. (2013) showed significant difference in hemoglobin values in the pre- and post-operative periods. Wang et al. (2015) showed that declines in hemoglobin values after CS was significantly less in TXA group than in control group Lakshmi et al. (2016). Percentage of fall in hemoglobin before and after surgery, and the number of subjects who had more than $10 \%$ fall in hemoglobin. $9.3 \%$ of subjects in study group and $39 \%$ of subjects in control group had more than $10 \%$ fall in hemoglobin. $\mathrm{Hb}$ after CS was significantly greater in tranexamic group than control group.

In our study, there was a significant statistical difference in the vital data postoperatively between the two groups. Postoperative hemoglobin was significantly higher in study group than control group. Reduction in hemoglobin was significantly less in study group than control group. Also, post-operative hematocrit was significantly higher in study group than control group. Reduction in hematocrit was significantly less in study group than in control group. These results agreed with the results of the previous mentioned studies.

Movafegh et al. (2011) and Goswami et al. (2013) showed no statistically significant difference in the heart rates, respiratory rates and blood pressures in the two groups. Lakshmi et al. (2016) showed significant difference in the heart rates, respiratory rates and blood pressures in the two groups.

In our study, there was significant difference in vital data between the study group and control group post-oparative. The included patients were those who were term, singleton, going for elective cesarean section, and excluded patients with high risk of thrombo-embolism, antepartum hemorrhage, abnormal site of the placenta, macrosomic baby, twin pregnancy and polyhydramnios. Movafegh et al. (2011), Goswami et al. (2013), Wang et al. (2015) and Lakshmi et al. (2016) showed the same inclusion and exclusion criteria. 
We used placebo in the current study. Movafegh et al. (2011), Goswami et al. (2013), Wang et al. (2015) and Lakshmi et al. (2016) also used placebo.

\section{CONCLUSION}

The use of tranexamic acid prior to cesarean section was significantly effective in reducing blood loss during cesarean with no observed maternal or neonatal side effects.

\section{REFERENCES}

1. Ducloy-Bouthors AS, Jude B, Duhamel A, Broisin F, Huissoud $C$ and Keita-Meyer $H$. (2016): High-dose tranexamic acid reduces blood loss in postpartum haemorrhage. Critical Care,15(2): R117-119.

2. Goswami U, Sarangi S, Gupta $S$ and Babbar S. (2013): Comparative evaluation of two doses of tranexamic acid used prophylactically in anemic parturients for lower segment cesarean section: A double-blind randomized case control prospective trial. Saudi J Anaesth $.7(4): 427-31$.

3. Henry DA, Carless PA, Moxey AJ, O'Connell D, Stokes BJ and Fergusson DA. (2015): Antifibrinolytic use for minimizing perioperative allogeneic blood transfusion. The Cochrane Library, 19:(1):CD001886.pub4.

4. IKarnbo I, Bedi N, Dhillon BS and Saxena NC. (2012): A critical appraisal of cesarean section rates at leachinghospilals in India. Int $\mathrm{J}$ Gynecol Obstet., 79:151-8.

5. Lakshmi, S. D and Abraham, R. (2016): Role of Prophylactic Tranexamic Acid in
Reducing Blood Loss during Elective Caesarean Section: A Randomized Controlled Study. Journal of Clinical and Diagnostic Research(JCDR), 10:12-17-21.

6. Matteson KA, Rahn DD and Wheeler TL. (2013): Non-surgical management of heavy menstrual bleeding: A systematic review and practice guidelines. Obstetrics and Gynecology, 121(3):632 -639-643.

7. Movafegh A, Eslamian L and Dorabadi A. (2011): Effect of intravenous tranexamic acid administration on blood loss during and after cesarean delivery. International Journal of $\mathbf{J}$ Gynecology \& Obstetrics, 115(3):224-26.

8. Ray I, Bhattacharya R, Chakraborty S, Bagchi C and Mukhopadhyay S. (2017): Role of Intravenous tranexamic acid on caesarean blood loss: a prospective randomized study. J Obstet Gynaecol India, 66:347-352.

9. Viswanath $\mathrm{O}$, Santhosh $\mathrm{S}$ and Goldman $\mathrm{H}$. (2015): The evolving role of prophylactic use of tranexamic acid before cesarean section: balance between maternal benefits and unknown neonatal effects. Journal of Anesthesiology and Clinical Research.,4(1):44-7.

10. Wang HY, Hong SK, Duan Y and Yin HM. (2015): Tranexamic acid and blood loss during and after cesarean section: a meta-analysis. $\mathbf{J}$ Perinatol, 35(10):818-25. 


\section{دور حمض الترانيكساميك الوقائي في التقليل من فقلان الدم أثناء العملية القيصرية الاختياريه}

أحمد محمد السعداوى غانم, مفيد فوزى محمد, سمير خميس جلال

قسم النساء والتوليا, كليه الطب, جامعة الازهر

E-mail: elseadawy855@gmail.com

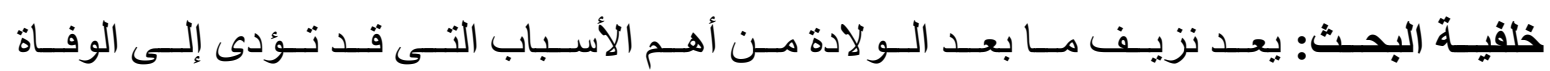

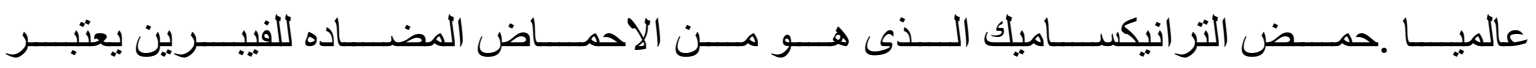
محاولة لمنع هذه المشكلة.

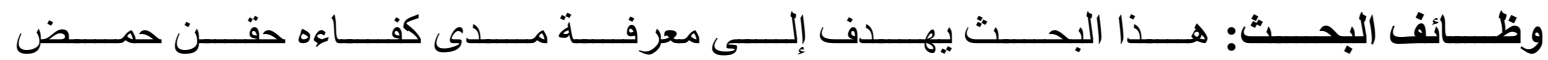
التر انيكساميك فى تقليل فقدان الدم أثناء الولادة القيصرية الاختيارية.

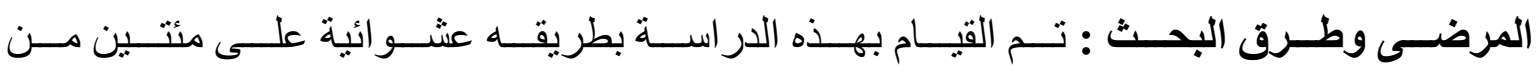

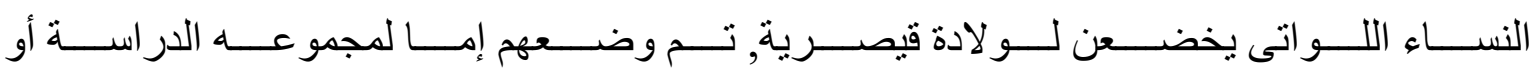

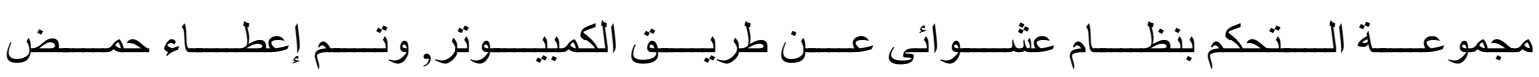

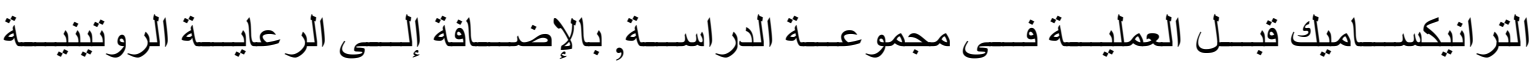

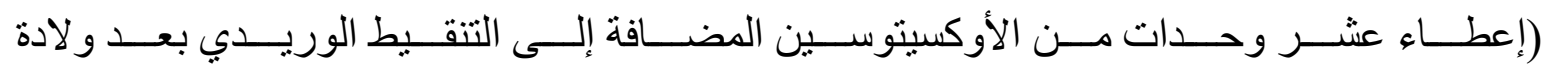

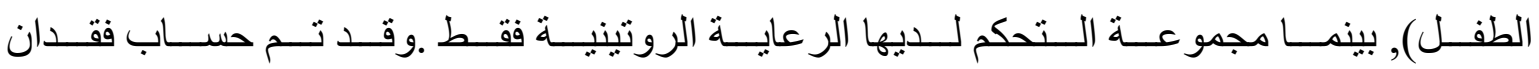
الدم, و الهيموجلوبين قبل وبعد العملية والمقارنة للنسبة المئوية للفرق بينهما.

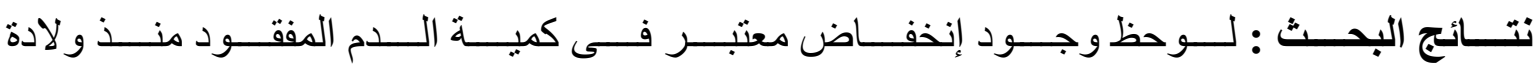

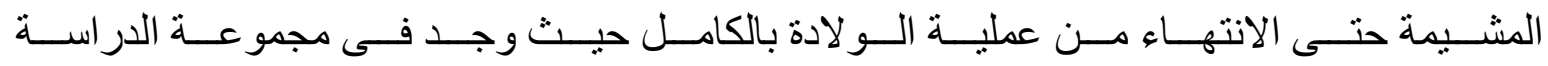

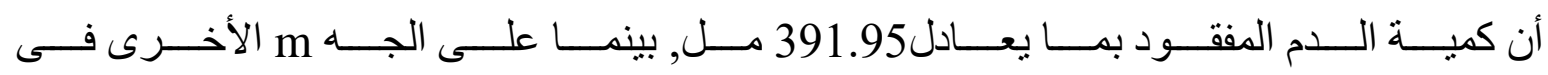

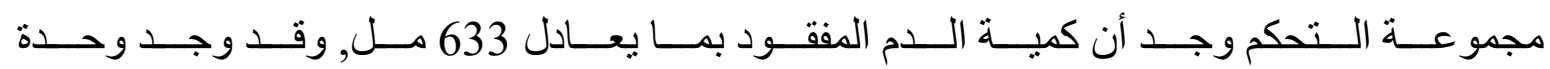

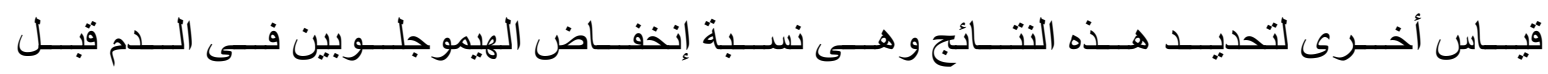

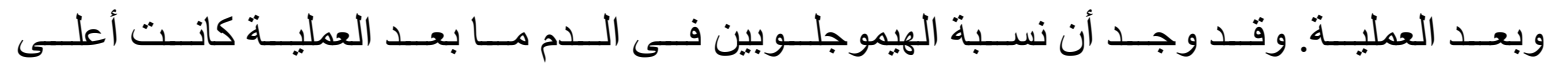

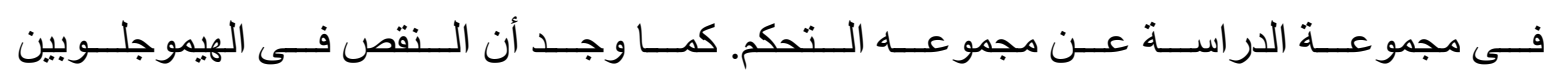

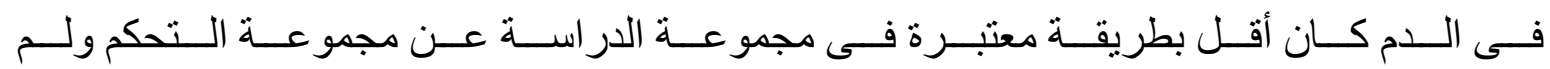
توجد أى مشاكل بعد العملية سواء للأم أو للمولود. 


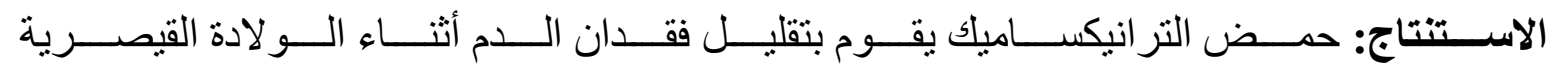

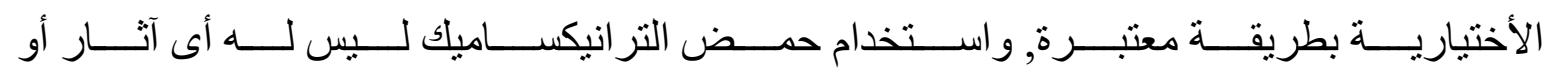

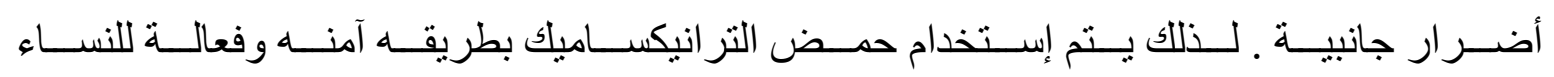
اللو اتى بخضعن لو لادة قيصرية.

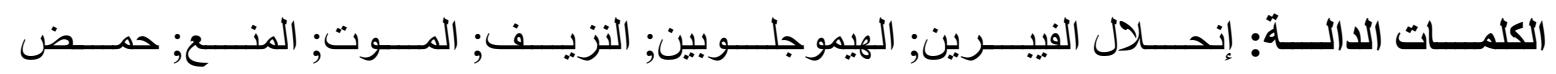
التر انيكساميك. 